\title{
Information Technology in Disaster Risk Reduction
}

\author{
Yuko Murayama ${ }^{1} \cdot$ Hans Jochen Scholl ${ }^{2} \cdot$ Dimiter Velev $^{3}$ \\ Published online: 7 October 2021 \\ (c) The Author(s), under exclusive licence to Springer Science+Business Media, LLC, part of Springer Nature 2021
}

\section{Introduction: IT in Disaster Risk Reduction}

It has been a decade since Japan had a catastrophe, the Great East Japan Earthquake and Tsunami on 11 March 2011. It caused severe damage to the northern coast of the main island of Japan and more than fifteen thousand eight hundred people died according to National Police Agency (2021). The disaster caused more global sustainable problems due to the nuclear power station incidents in Fukushima as in Kushida (2015).

Among the issues raised throughout the support for disaster response, there was no information system available in Japan at that time for immediate use in emergency response. For example, what was needed urgently a few weeks later than the catastrophe, was an information system for shelter management such that distribution of goods to shelters would be performed timely as reported in Murayama (2014). Eventually some industrial volunteers managed to implement such a system based on Sahana (Currion et al., 2007; $\mathrm{Li}$ et al., 2013), an information sharing system for humanitarian assistance at disaster developed originally by programmers in Sri Lanka as a free and open-source software just after the 2004 Indian Ocean earthquake and tsunami. However, a lot of customization was required and when the system was ready after one and a half months, it was too late

Yuko Murayama

murayama@tsuda.ac.jp

Hans Jochen Scholl

jscholl@uw.edu

Dimiter Velev

dgvelev@unwe.bg

1 Institute for Mathematics and Computer Science, Tsuda University, Tokyo, Japan

2 The Information School, The University of Washington, Seattle, WA, USA

3 Science Research Center for Disaster Risk Reduction, University of National and World Economy, Sofia, Bulgaria for practical use as victims were about to move to temporary housing from the shelters.

The research domain of information technology in disaster risk reduction is relatively new although disaster issues have been researched so long. Three prior special issues of Information Systems Frontiers have looked at this aspect. The pioneer issue edited by Janssen et al. (2010) looked into multi-agency disaster management and suggested a need to relate practice and theory by using human-centered approaches. Beydoun et al. (2018) followed this course with semantic technologies, and further analysis of related organizational theories, interoperability and IS readiness issues in disaster management. Ghosh et al. (2018) presented the use of social media content in disaster situations. Compared to those past special issues, this issue includes relatively more practical issues looking at human aspects as we introduce them in the next section.

Regarding information technology in disaster risk reduction for natural disasters, researchers in disaster science have looked into the environmental mechanisms and risks (e.g. Imamura et al., 2006; Bernard and Robinson, 2009). They have used information technologies available for their work. On the other hand, researchers from IT have been involved in disaster management since 1970s. Turoff (2002) and Van de Walle et al. (2009) presented the interdisciplinary nature of the research domain of information systems for emergency management. They set up a community, ISCRAM (Information System for Crisis Response and Management) for this area of research in 2004 and have held annual conferences including practitioners.

By taking similar perspectives, the International Federation for Information Processing (IFIP) has set up a domain committee and a working group on IT in Disaster Risk Reduction (ITDRR) to promote this exciting area of research and development. IFIP has held its annual workshop and conferences since 2016. In this special issue, several papers are from these conferences.

Due to the recent environmental changes, including global warming, we are facing an unexpected number of natural disasters and crises as well as their related consequences. 
Moreover, the recent global pandemic by COVID19 has brought us a great concern on how we communicate with each other in our societies. Remote meetings and events are more popular ever than before as the new normal, showing how information technologies could be of use at disaster.

We are also facing another era of Industrial Revolution: information technologies including artificial intelligence (AI) and social media are popular and used in daily life. Yet, they are not used fully in relief activities and in response to disasters. International differences in IT literacy as well as in IT equity might be among the reasons for this lack of use. In this special issue, these issues are explored as well from the viewpoint of the Sustainable Development Goals (SDGs) of the United Nations (UN). UN set up seventeen SDGs towards 2030 described in the 2030 Agenda for Sustainable Development according to United Nations (2015). Those goals include ending poverty with strategies that build economic growth and address a range of social needs including education, health, social protection, and job opportunities, while tackling climate change and environmental protection. Disaster risk reduction has been categorized in Goal 11, "Make cities inclusive, safe, resilient and sustainable," on the other hand, disaster may effect all the SDGs, so that it should be looked at with wider viewpoints. Indeed, IT in disaster risk reduction cannot not be resolved only from the technological viewpoint. What we need presumably is to get together with researchers from diverse research domains such as social science. This is one of the conclusions from a workshop on IT in disaster risk reduction which was organized at the World Summit on the Information Society (WSIS) Forum 2021 as in ITU (2021).

The issues in IT in disaster risk reduction are of a multidisciplinary nature and include various aspects of research areas such as information systems; IT; natural disaster sciences such as meteorology, social media, risk management, education, psychology and economics; and practical and strategic issues such as disaster management and policy making.

The aim of this special issue is to promote this multi-disciplinary area of research and development, and to encourage researchers and practitioners who work on information technologies to look into disaster issues including disaster management and disaster science as promising applications.

\section{The Special Issue}

We have selected nine papers for the present special issue and four more papers for the general issue after a thorough reviewing process from twenty submitted to the call and a multitude more that were submitted to the workshops. The special issue includes five papers whose earlier versions were presented at ITDRR conferences; these papers contain significant extensions based on the feedback received at the conferences.

The accepted papers fall into five topics, viz. (1) human behavior at disaster, (2) use of social media for disaster management, (3) situation awareness at disaster, (4) inclusive support at disaster, and (5) 3C model. Situation awareness has been researched for long in ergonomics originally on aviation for aerial warfare, e.g. Endsley (1988). It has been applied to disaster management and became one of the major issues, e.g. Harrald and Jefferson (2007) and many others such as Johnson et al (2011) and Sophronides et al (2017). The $3 \mathrm{C}$ model is from the groupware research domain, which looks at collaboration in terms of communication, coordination and cooperation, e.g. Fuks et al. (2008).

\subsection{Human Behavior in Disasters}

Two papers look into human behavior. The paper by Young and Aguirre (2021), entitled "PrioritEvac: An Agent-Based Model (ABM) For Examining Social Factors of Building Fire Evacuation," describes an agent-based model with social dimensions of fire evacuation and responses to fire and smoke as well as simulation results for the station nightclub fire. It demonstrates that human behavior should be taken into consideration in such models.

The paper by Mirbabaie et al. (2021) entitled "Digital Nudging in Social Media Disaster Communication" investigates the possibility of the use of nudging, a form of behavior adjustment in social media so that emergency management agencies can make use of social media for information sharing with public. Literature survey and qualitative analysis with social media data were used. The paper could be categorized in the second group, the use of social media as well.

\subsection{Use of Social Media for Disaster Management}

Four papers presented the work using social media. The paper by Uchida et al. (2021), entitled "Development and Implementation of an ICT-based Disaster Prevention and Mitigation Education Program for the Young Generation" introduces an education program for young people to raise awareness of disaster prevention and mitigation making use of social media. The program consists of workshops for town watching and group discussion using DITS/DIMS (disaster information tweeting and mapping system).

The paper by Arapostathis (2021), entitled "A methodology for automatic acquisition of flood-event management information from social media: The flood in Messinia, South Greece, 2016" applies machine learning to classify Twitter content and glocalization methods to support decision making by professional responders. The research aims at providing real-time information from analyzed tweet and 
the paper provides improvements to post-hoc analyses and after-action reports, which are used for the next round of emergency response planning and preparedness planning.

The paper by Mendon et al. (2021) entitled "A hybrid approach of machine learning and lexicons to sentiment analysis: Enhanced insights from Twitter data of natural disasters" utilizes machine learning algorithms revolve around unsupervised approach and lexicon-based approach to produce a framework for sentiment analysis on Twitter on natural disasters, Kerala floods in 2018.

The paper by Abouzeid et al. (2021) entitled "Learning Automata-based Misinformation Mitigation via Hawkes Processes" proposes a method to mitigate the effect of misinformation based on the learning of social media single user models, using decentralized Learning Automata (LA) to control Multivariate Hawkes Processes (MHP).

\subsection{Situation Awareness at Disaster}

Four papers examine situation awareness. The paper by Fromm et al. (2021), entitled "Social Media Data in an Augmented Reality System for Situation Awareness Support in Emergency Control Rooms" proposes how an Augmented Reality with the information from social media such as twitter could be of use for situation awareness in emergency control rooms.

The paper by Tanzi and Bertolino (2021) entitled "Autonomous Systems for Rescue Missions: design, architecture and configuration validation" reports on an autonomous system, ArcTurius, a rover whose primary objective is the precise location of survivors upon earthquakes. The system was validated in terms of design through simulation and formal verification. Although the authors does not mention situation awareness explicitly, the work presented is used to support for it.

The paper by Horita et al. (2021) entitled "Exploring the use of IoT data for heightened situational awareness in centralized monitoring control rooms" presents an qualitative case study within a centralized monitoring control room of a Brazilian early-warning centre with IoT sensor data from local places for situation awareness of local conditions by the qualified experts in the central control.control room operators.

The paper by Fujita and Hatayama (2021) entitled "Estimation Method for Roof-damaged Buildings from AeroPhoto Images during Earthquakes using Deep Learning" presents the development of a system for the estimation of damages in buildings after an earthquake, based on deep learning applied to aero photos with the location information by Geographic Information System (GIS) so that the Japanese government can issuing damage certificates more efficiently. Although the authors does not mention situation awareness explicitly, the work presented is used to support for it.

\subsection{Inclusive Support at Disaster}

Two paper look into the inclusive aspects at disaster. The paper by Sasaki and Kitsuya (2021), entitled "Development and Evaluation of Regional Information Sharing System (RISS) for Disaster Risk Reduction" reports a use of Regional Information Sharing System (RISS) to provide the citizens with the information for daily life as well as the one for disaster risk reduction in case of emergency. The system was provided for inclusive support so that those such as the elderly without smartphone could make use of it as well. The paper presents the results from field tests.

The paper by Gjøsæter et al. (2021) entitled "Universal Design of ICT for Emergency Management from Stakeholders' Perspective -A Systematic Literature Review" reports the current state of inclusive aspects of ICT for emergency management based on a systematic literature survey on universal design, ICT and emergency management between 2008 to 2020 using predefined frameworks.

\subsection{Model}

One paper is related to the $3 \mathrm{C}$ model in this special issue. The model could be looked at more for disaster management since collaboration is an important aspect for disaster response and management.

The paper by Simona et al. (2021), entitled "A Scoping Review on Agency Collaboration in Emergency Management Based on the 3C Model" analyses the technological support to collaboration services in emergency management by literature review based on the 3C Model.

The paper on situation awareness by Horita et al. (2021) investigated collaboration in the control room operators.

\section{Future Research}

Disaster risk reduction is a promising research and practical domain for information technologies. We have introduced a small number of the examples in this special issue. What is exciting about this research domain is that the research results may well be connected to humanitarian aid. We hope that many of the readers would start thinking what contributions they could make.

There are many open issues that are yet to be tackled. We highlight a few of them.

For situation awareness (SA), team SA is suggested by Endsley (1995), which would be more applicable to emergency response and management compared to individual SA. Endsley and Jones (2001) suggest inter-team SA which 
would be required in disaster response with stakeholders with different perspectives and cultures. Kanno et al. (2013) try and incorporate mutual belief to team SA.

Trust issues are another aspect to be researched in disaster management. Murayama et al. (2013) present the needs of trust for disaster response from their experience of IT support for disaster response at the Great East Japan Earthquake and Tsunami.

Social science approaches are applied in Disaster Risk Reduction, such as the use of qualitative research. White et al. (2009) suggested the use of social media for emergency management and Hiltz et al (2014) conducted interview with emergency managers on the use of social media.

There are many more issues we can expect in this research domain such as the use of $3 \mathrm{C}$ model for collaboration in disaster response and management, as well as inclusive issues such as usability and situational disability. For instance, inclusive issues (Malteser International, 2015) and cyber security issues are equally important for disaster response and resilience. We expect more papers may well be coming from the security and privacy domain in future. Security incidents are disasters, indeed and there would be more opportunity to apply disaster response and management to security as well as to look into the security and privacy aspects in disaster management.

Acknowledgements We sincerely thank the authors who submitted their papers to this special issue and the reviewers as follows for this special issue.

\section{References}

Abouzeid, A., Granmo, O.-C., Webersik, C., \& Goodwin, M. (2021). Learning automata-based misinformation mitigation via Hawkes processes. Information Systems Frontiers. https://doi.org/10.1007/ s10796-020-10102-8

Arapostathis, S. G. (2021). A methodology for automatic acquisition of flood-event management information from social media: The flood in Messinia, South Greece, 2016. Information Systems Frontiers. https://doi.org/10.1007/s10796-021-10105-z

Bernard, E. N., \& Robinson, A. R. (Eds.) (2009). The Sea, Volume 15: Tsunamis. Harvard University Press

Beydoun, G., Dascalu, S., Dominey-Howes, D., et al. (2018). Disaster management and information systems: Insights to emerging challenges. Information Systems Frontiers, 20, 649-652. https://doi. org/10.1007/s10796-018-9871-6

Currion, P., Silva, C., \& Van de Walle, B. (2007). Open source software for disaster management. Communication of ACM, 50(3), 61-65. https://doi.org/10.1016/j.dss.2012.10.030

Endsley, M. R. (1988). Design and evaluation for situation awareness enhancement. In Proc. the annual meeting human factors society, (Vol. 32, pp. 97-101). SAGE Publications Sage CA.

Endsley, M. R. (1995). Toward a theory of situation awareness in dynamic systems. Human Factors Journal, 37(1), 32-64.

Endsley, M. R., \& Jones, W. M. (2001). A model of inter- and intrateam situation awareness: implications for design, training and measurement. In M. McNeese, E. Salas, \& M. Endsley (Eds.),
New trends in cooperative activities: Understanding system dynamics in complex environments. Human Factors and Ergonomics Society.

Fromm, J., Eyilmez, K., Baßfeld, M., Majchrzak, T. A., \& Stieglitz, S. (2021). Social media data in an augmented reality system for situation awareness support in emergency control rooms. Information Systems Frontiers. https://doi.org/10.1007/s10796-020-10101-9

Fujita, S., \& Hatayama, M. (2021). Estimation method for roof-damaged buildings from aero-photo images during earthquakes using deep learning. Information Systems Frontiers. https://doi.org/10. 1007/s10796-021-10124-w

Fuks, H., Raposo, A., \& Gerosa, M. (2008). The 3C collaboration model. In Encyclopedia of ecollaboration (pp. 637-644). IGI Global.

Ghosh, S., Ghosh, K., Ganguly, D., et al. (2018). Exploitation of social media for emergency relief and preparedness: Recent research and trends. Information Systems Frontiers, 20, 901-907. https://doi. org/10.1007/s10796-018-9878-z

Gjøsæter, T., Radianti, J., \& Chen, W. (2021). Universal design of ICT for emergency management from stakeholders' perspective-A systematic literature review. Information Systems Frontiers, 23(5), 56. https://doi.org/10.1007/s10796-020-10084-7

Harrald, J., \& Jefferson, T. (2007). Shared situational awareness in emergency management mitigation and response. In Proc. HICSS40 (pp. 23-23). IEEE, Waikoloa, HI.

Hiltz, S.R., Kushma, J., \& Plotnick, L. (2014). Use of social media by U.S. public sector emergency managers: Barriers and wish lists. In Proc. 11th international conference on information systems for crisis response and management (ISCRAM), ID11, University Park, PA, USA.

Horita, F. E. A., Baptista, J., \& de Albuquerque, J. (2021). Exploring the use of IoT data for heightened situational awareness in centralized monitoring control rooms. Information Systems Frontiers. https://doi.org/10.1007/s10796-020-10075-8

Imamura, F., Yalciner, A. C., \& Ozyurt, G. (2006). Tsunami Modelling Manual (TUNAMI model) (2006). Retrieved May 25, 2021, from http://www.tsunami.civil.tohoku.ac.jp/hokusai3/J/projects/ manual-ver-3.1.pdf

International Telecommunication Union (ITU). (2021). IT in Disaster Risk Reduction (ITDRR), International Federation for Information Processing (IFIP) Workshop, https://www.itu.int/net4/wsis/ forum/2021/Agenda/Session/257. Accessed 31 July 2021

Janssen, M., Lee, J., Bharosa, N., et al. (2010). Advances in multiagency disaster management: Key elements in disaster research. Information Systems Frontiers, 12, 1-7. https://doi.org/10.1007/ s10796-009-9176-x

Johnson, D., et al. (2011). Improved situational awareness in emergency management through automated data analysis and modeling. Journal of Homeland Security and Emergency Management. https://doi.org/10.2202/1547-7355.1873

Kanno, T., Furuta, K., \& Kitahara, Y. (2013). A model of team cognition based on mutual beliefs. Theoretical Issues in Ergonomics Science, 14(1), 38-52. https://doi.org/10.1080/1464536X.2011. 573010

Kushida, K. E. (2015). The Fukushima Daiichi Nuclear Power Station disaster: Investigating the myth and reality. Social Science Japan Journal, 18(2), 276-279. https://doi.org/10.1093/ssjj/jyv021

Li, J. P., Chen, R., Lee, J. K., \& Rao, H. R. (2013). A case study of private-public collaboration for humanitarian free and open source disaster management software deployment. Decision Support Systems, 55(1), 1-11. https://doi.org/10.1016/j.dss.2012.10.030

Malteser International. (2015). "Barrier-free" - Including people with disabilities in disaster prevention in Myanmar. https://www.youtu be.com/watch?v=uzSKfx2sbdY. Accessed 31 July 2021

Mendon, S., Dutta, P., Behl, A., \& Lessmann, S. (2021). A hybrid approach of machine learning and lexicons to sentiment 
analysis: Enhanced insights from Twitter data of natural disasters. Information Systems Frontiers. https://doi.org/10.1007/ s10796-021-10107-x

Mirbabaie, M., Ehnis, C., Stieglitz, S., Bunker, D., \& Rose, T. (2021). Digital nudging in social media disaster communication. Information Systems Frontiers. https://doi.org/10.1007/ s10796-020-10062-Z/

Murayama, Y., Saito, Y., \& Nishioka, D. (2013). Trust issues in disaster communication. In Proc. the 46th Hawaiian international conference on system sciences (HICSS-46) (pp. 335-342).

Murayama, Y. (2014). Issues in disaster communications. Journal of Information Processing, 22(4), 558-565. https://doi.org/10.2197/ ipsjjip. 22.558

National Police Agency. (2021). Damage of 2011 Great East Japan earthquake and tsunami and police response (in Japanese), https:// www.npa.go.jp/news/other/earthquake2011/pdf/higaijokyo.pdf. Accessed 31 July 2021

Sasaki, J., \& Kitsuya, M. (2021). Development and evaluation of regional information sharing system (RISS) for disaster risk reduction. Information Systems Frontiers. https://doi.org/10.1007/ s10796-020-10076-7

Simona, T., Taupo, T., \& Antunes, P. (2021). A scoping review on agency collaboration in emergency management based on the 3C model. Information Systems Frontiers. https://doi.org/10.1007/ s10796-020-10099-0

Sophronides, P., Papadopoulou, C. A., Giaoutzi, M., \& Scholten, H. (2017). A common operational picture in support of situational awareness for efficient emergency response operations. Journal of Future Internet, 2(1), 10-35. https://doi.org/10.18488/journal. 102.2017.21.10.35

Tanzi, T., \& Bertolino, M. (2021). Autonomous systems for rescue missions: design, architecture and configuration validation. Information Systems Frontiers. https://doi.org/10.1007/ s10796-020-10085-6

Turoff, M. (2002). Past and future emergency response information systems. Communication of the ACM, 45(4), 29-32.

Uchida, O., Tajima, S., Kajita, Y., Utsu, K., Murakami, Y., \& Yamada, S. (2021). Development and implementation of an ICT-based disaster prevention and mitigation education program for the young generation. Information Systems Frontiers. https://doi.org/10. 1007/s10796-020-10082-9

United Nations. (2015). Transforming our world: The 2030 agenda for sustainable development. https://sustainabledevelopment.un. org/content/documents/21252030\%20Agenda\%20for\%20Sustaina ble\%20Development\%20web.pdf. Accessed 31 July 2021

Van de Walle, B., Turoff, M., \& Hiltz, S. R. (Eds.). (2009). Information systems for emergency management. M.E. Sharpe.

Vieweg, S., et al. (2010). Microblogging during two natural hazards events: What Twitter may contribute to situational awareness. In Proc. CHI2010, ACM, Atlanta, GA, USA (pp. 1079-1088).

White, C., Plotnick, L., Kushma, J., Hiltz, S. R., \& Turoff, M. (2009). An online social network for emergency management. International Journal of Emergency Management, 6(3-4), 369-382.

Young, E., \& Aguirre, B. (2021). PrioritEvac: An agent-based model $(\mathrm{ABM})$ for examining social factors of building fire evacuation. Information Systems Frontiers. https://doi.org/10.1007/ s10796-020-10074-9

Publisher's Note Springer Nature remains neutral with regard to jurisdictional claims in published maps and institutional affiliations.
Yuko Murayama is a researcher at Institute for Mathematics and Computer Science, Tsuda University, as well as Professor Emeritus at Iwate Prefectural University, Japan. Her research interests include internet, network security, security, trust, anshin, and disaster information processing. She had a B.Sc. in Mathematics from Tsuda College, Japan in 1973 and had been in industry in Japan. She had M.Sc. and Ph.D. both from University of London (attended University College London) in 1984 and 1992, respectively. She had been a visiting lecturer from 1992 to 1994 at Keio University, and a lecturer at Hiroshima City University from 1994 to 1998. She was with Iwate Prefectural University from 1998 to 2016. She was a professor at Tsuda University from 2016 to 2019. She served as an IFIP Vice President and now is Chair of IFIP WG5.15 on IT in Disaster Risk Reduction. She is an IPSJ fellow and a senior life member of IEEE, as well as a member of ACM, IPSJ and IEICE.

Hans Jochen Scholl serves as a Full Professor with tenure in the Information School at the University of Washington (UW), Seattle, WA. From the University of Albany, NY/SUNY he earned a Ph.D. in Information Science. He also holds a Master's degree in Business Administration from the GSBA Zurich, Switzerland. His research interests are focused on disaster information management, smart governance/government, and information artifact evaluation. Jochen is a past president of the Digital Government Society, of which he was a founding member. He also serves as Past Chair of the IFIP WG 8.5 (IS and Public Administration) and as Board Member of the International Association for Information Systems for Crisis Response and Management (ISCRAM). With help of UW Information School graduate assistants, he also maintains and publishes the Digital Government Reference Library (DGRL) and the Disaster Information Reference Library (DIRL). For a decade and a half, Jochen served as chair of the renowned Digital Government Track at HICSS. He also contributes as Associate Editor and Editorial Board Member on a number of leading journals.

Dimiter Velev is a Professor with the Department of Information Technologies and Communications at the University of National and World Economy (UNWE), Sofia, Bulgaria. Dimiter Velev is the Director of the Science Research Center for Disaster Risk Reduction at UNWE. He holds a M.Sc. degree in Electro-Engineering from the Sofia Technical University, Bulgaria and a Ph.D. degree in Computer systems, Complexes, Systems and Networks from the Pukhov Institute for Modelling in Energy Engineering at the National Academy of Sciences of Ukraine. Prof. Velev is a member of the International Federation for Information Processing (IFIP), http://ifip.org/, in which he is the Vice-chair of IFIP TC5 New Activities and Interdisciplinary Research and the Secretary of IFIP WG 5.15 Information Technology in Disaster Risk Reduction. Prof. Velev's main areas of academic and R\&D interest are Information Technology, Web Science, Cloud Computing, Mobile Computing, Online Social Networks, Integrated Information Systems for Disaster Management, Artificial Intelligence, Cybersecurity, XR. He is a regular chair and a keynote speaker of conferences in Asia and Europe and a reviewer of many scientific publications in journals and conferences. He has published more than 200 ICT-related papers. 